\title{
On the Compilation and Construction of Campus Culture of University Archives
}

\author{
Qun Li \\ Jilin Agricultural University, Changchun of China \\ Liqun1968@126.com
}

Keywords: University archives compilation; Campus culture

\begin{abstract}
Archives compilation is an important service of Higher Vocational Colleges archives department. The archives compilation work quality and level directly reflects the archives service quality and scientific level, this work also in spreading and promoting campus culture plays a crucial role in the ${ }^{[1]}$. First discussed the research work in the construction of campus culture the role of editing files of higher vocational colleges, followed by analysis of the higher vocational colleges archives compilation of existing problems, finally put forward to improve the archives compilation work, relevant strategies to promote the construction of campus culture.
\end{abstract}

\section{Research on the Construction of Campus Culture in the Role of University Archives Compilation}

\section{The Continuation of Campus Culture}

The university is a carrying countless students dream of place, also is the high skilled personnel training base. Not only the responsibility of imparting knowledge and skills, more important is carrying the culture mission. Archives of higher vocational schools Hall (room) as the campus culture and Heritage Department records, has always played an important role in the construction of campus culture. The archives compilation work is archives (room) as an important business sector. The content of cultural institutions of higher education can be combined with their own actual situation, starting from the perspective of teachers and students, select the file contents of the compilation.

Compilation is the main content of the Yearbook, memorabilia, organization, documents such as ${ }^{[2]}$, these achievement, a true record of the development of higher vocational colleges, not only store and record the previous campus culture, is that people know and understand the important way of campus culture, but also provides a basis for nutrient and our school campus cultural construction.

\section{Carry Forward the Historical Culture}

The archives and records of the school has a long history, glorious tradition and fine style of study. The achievement can not only enrich the history of the content is complete and detailed files, can also spread history culture. The university archives department can make full use of the history of the precious cultural wealth of history, with historical inspiration ${ }^{[3]}$, to enhance the school honor. Sense of responsibility and mission, and by understanding the history of the school, school tradition and the predecessors deeds, students can broaden their horizons, increase knowledge, edify sentiment, self shaping, grinding and willpower.

\section{Promote the Construction of Campus Culture Consciousness}

The overall situation is the aim of university archives archives management and archives management. To change the passive state in the past unknown to the public, from the back to the front, give full play to the advantages of innovation of archival information resources, archives culture, build archives culture brand ${ }^{[4]}$. through the Internet, media, windows, billboards and other ways to set up lectures on special topics the characteristics of archival information, publicity reports. Put the archives work into the construction of campus culture of the track, establish archives culture construction concept, the static silent data, developed into Shengwen Mao, style novel, close to the actual construction of the campus culture, shocking educational resources.

University Archives should make full use of the advantages of our era, network play a role in the 
construction of campus culture, firmly grasp the sovereignty of archives compilation in the construction of campus culture, editing and research to expand the new space of campus cultural construction of archives ${ }^{[5]}$, the archive compilation achievement through the network platform to become the new position of campus culture the construction of university archives, but also continue to develop new elements, compiling new achievements, establish a new concept of campus culture construction in the new period.

\section{Research the Problems of University Archives Compilation}

\section{The Collection is Not Rich}

Our universities construction scale, the history of irregular length, educational philosophy and nature are different, therefore, the University Archives (room) and the number of hidden structures are not the same, the majority of colleges and universities teaching documents, archives Hall (room) accounted for the vast majority of Tibet, lack of science and technology archives reflect the characteristics of the university archives, the lack of file structure is not reasonable, the contents of the narrow coverage, coupled with the hall (room) archives information is outdated and largely restricted to the university archives compilation work carried out in-depth. The reason is the lack of awareness of the importance of archives work, the collection measures are not effective, collect a single way, collecting channel Flow induced by ${ }^{[6]}$.

\section{The Archives Management Personnel Quality Problem}

Due to the influence of traditional concepts, many colleges and universities that archives work is nothing more than a collection, finishing only because. The majority of personnel archives work in Colleges and universities with less, archivists often are a multitasked ${ }^{[7]}$, more time and energy to input to compilation work. Then combined with the educational level of personnel files is low, archives of professional technical education is very rare and difficult to come up with high quality achievement, therefore in the construction and development of in the process of University's lack of attention and support. This not only dampened the enthusiasm of the work of personnel files, but also caused the team of archives work is not stable.

\section{The Low Level of Achievement}

Due to the influence of factors such as personnel, the majority of University Archives (room) the focus of work in the collection of archives Keep and use, as an important part of the archives compilation work often is not into the proper position, sometimes in order to upgrade standards and meet all kinds of inspection and assessment, temporary personnel assault, often confined to the eye such as memorabilia, Yearbook, documents and materials, organization, basic introduction meeting other topics. Compilation compilation series not only research work, and the center of the school, not hot work closely, are some of the most primitive material summary and collection of information content is low, long cycle, pertinence and practicability, and utilization of low value, unable to arouse everyone on the achievement of confidence and enthusiasm.

\section{To Strengthen the Archives Compilation Work, Countermeasures to Promote the Construction of College Culture}

\section{Give Full Play to the Cultural Function of Archives}

Archives compilation is one of the important ways of archives culture function, through the compilation, the continuous development of archival resources, make the file out of the archives, to campus to student services for students and staff. The University Archives contains rich humanistic spirit and scientific spirit, cultural and educational function of college archives, to cultivate students' moral character, personality, especially on non intellectual factors such as humanistic spirit, team consciousness and the cultivation of spirit of cooperation and the magic will have an important role. According to actual needs, make full use of file processing for two times and three times. The literature documents such as can write school chronicle history, The organization of teachers and students, honor book, teacher story book, well-known alumni, students struggle together, employment situation of graduates, graduate talent book, published by ${ }^{[8]}$. books of propaganda and 
utilization, enable teachers and students to fully understand the cultural connotation of archives, archives of cultural value, give full play to the cultural function of archives to archives for the construction of campus culture, contribute to higher education.

\section{To Improve the Archives Compilation Work Innovation}

Each university should set up a Compilation Committee organized experience files, make archives compilation in a planned, targeted, a program, a focused, so that the archives work in Colleges and universities to further standardize and legalization, to quantify and manage the specific work. The compilation work a school building can use the university archives, the development of information resources. The current work on archives without what practical rules, and the archives work of colleges and universities of many types and styles, but the quantity and quality that how many are just passable, so the archives departments to strengthen the establishment of scientific regulation. The archives compilation and evaluation mechanism, and specialized evaluation organization, established some mutual evaluation activities ${ }^{[9]}$. if there is no compilation of scientific evaluation mechanism of archives, it is not comprehensive, scientific, and effectively carry out the archives compilation work. A compilation of scientific and reasonable evaluation system of archives, can deepen the archives compilation work can increase the archives compilation work in theoretical depth, can make the archives more scientific.

\section{To Cultivate High-Quality Talents to Master New Skills Compilation}

The archives compilation work in a transaction, professional and knowledge as a whole, to adapt to the actual needs, we should actively cultivate and improve the archives staff business ability and quality, compilation quality, better service for the construction of school culture. First, archives management personnel professional structure should be reasonable, there is a clear division of labor, and remained relatively stable; secondly, the existing staff to strengthen the compilation of business skills and education, science and technology training, the establishment of knowledge structure should, improve the comprehensive ability of the editorial and research staff; thirdly, with the file management information and multimedia development, archives personnel should also keep pace with the times, to inject new knowledge, Master new skills.

The road ahead will be long, the archives compilation work is long way to go ${ }^{[10]}$. new period, file management and editorial and research staff, the concept should be updated to keep pace with the times, bold innovation, seize the development of schools and cultural construction to the archives compilation work opportunities, timely adjustment of archives compilation concept, improve the quality and efficiency of research work for the school archives school culture, enhance the strong strength, make a contribution to the school work.

\section{Summary}

In summary, editing and research work mainly includes the education of university archives, basic work, equipment, honor and administrative management work. Through the archives compilation and rich collection of campus culture, and the construction of campus culture and enrich the connotation of archives research work, therefore, do a good job in the school archives management, pay attention to archives research, has a positive role to enrich the school culture, but also to strengthen the construction of school culture, enrich the school archives work contents and types.

\section{References}

[1] Wenhui Bao. The construction of campus culture and the social responsibility of the library of [J]. science and technology information development and economy. 2014 (9): 48-50.

[2] Qiang Meng. 1989-2015 university archives compilation overview of [J]. office business. 2016 (17): 136-138.

[3] Jinling Dong Research on editing of University Archivesh [J]. Inside and outside of Lan Tai. 2017 (1): 46.

[4] Xianping Jiang, Jiebin Lang. Journal of the University Library and the construction of new campus culture $[\mathrm{J}]$. university library. 2013 (3): 50-54. 
[5] Dan Liu. Journal of research work new ideas [J]. Hubei Adult Education College of university archives. 2015 (3): 70-72.

[6] Boyu Dong . Research work existence and strategy of university archives compilation [J]. salon inspirational. 2016 (21): 43.

[7] Caifu Li, Nuo $\mathrm{Xu}$. University archives compilation and construction of campus culture in the role of [J]. in Beijing archives. 2015 (2): 24-26.

[8] Junlan Jin. Do this work to promote the construction of campus culture of University Archives [J]. Journal of Hubei Normal University (PHILOSOPHY AND SOCIAL SCIENCE EDITION). 2012 (5): 146-148.

[9] Yan Mu. Research on Countermeasures of occupation college students' cognitive status and campus culture -- a case study of Shenzhen Polytechnic [J].. Journal of Xingtai Polytechnic College 2015 (1): 31-34.

[10] Yaping Fan. The archives compilation work thinking and practice of the $[\mathrm{J}]$. archives in Shaanxi. 2016 (1): 39. 